\title{
A new species of the "condylarth" Hyopsodus from the middle Eocene of the Erlian Basin, Inner Mongolia, China, and its biostratigraphic implications
}

Bin Bai, Yuan-Qing Wang, Xin-Yue Zhang, and Jin Meng

Acta Palaeontologica Polonica 66 (4), 2021: 767-777 doi:https://doi.org/10.4202/app.00908.2021

The "condylarth" genus Hyopsodus is diverse and abundantly represented in Eocene mammalian faunas of North America. In contrast, fossil specimens of Hyopsodus are rather sparse in Eurasia. Only four species of Hyopsodus are known from Asia and two from Europe, as compared to the 17 species of Hyopsodus described from North America. Here, we report a new species of Hyopsodus, Hyopsodus arshantensis sp. nov., from the middle part of the Arshanto Formation in the Erlian Basin, Inner Mongolia, China. The holotype and only specimen of the new species, a right mandible with $\mathrm{m} 1-\mathrm{m} 2$, exhibits a unique combination of characters on m1-m2 not present in other species of Hyopsodus, including a moderately lophodont crown, a long trigonid without a paraconid, an obliquely aligned protolophid, an angle between the cristid obliqua and the posthypocristid slightly greater than $90^{\circ}$, a midline position of the hypoconulid, and a relatively large entoconid. The $\mathrm{m} 1-\mathrm{m} 2$ morphology of $H$. arshantensis arshantensis is intermediate between specimens of Hyopsodus from the Wasatchian and Uintan North American Land Mammal Ages (NALMA), and is comparable to that of Hyopsodus from the Bridgerian NALMA. Moreover, its relatively large size is near the size range present among specimens of the late Bridgerian $H$. marshi. Based on those similarities, in combination with a few fossil mammals from overlying layers, the middle part of the Arshanto Formation could be correlated in part to the late Bridgerian, and the upper part of the Arshanto Formation may bracket the time interval equivalent to the Bridgerian/Uintan boundary. That proposed correlation and somewhat different faunas recognized within the Arshanto Formation suggest that it may be necessary to subdivide the Arshantan Asian Land Mammal Age (ALMA) and/or redefine the Arshantan/Irdinmanhan ALMA boundary in future comprehensive studies.

Key words: Mammalia, Hyopsodus , “condylarth”, Eocene, Arshanto Formation, Erlian Basin, China.

Bin Bai [baibin@ivpp.ac.cn] (corresponding author), Key Laboratory of Vertebrate Evolution and Human Origins of Chinese Academy of Sciences, Institute of Vertebrate Paleontology and Paleoanthropology, Chinese Academy of Sciences, Beijing 100044, China; CAS Center for Excellence in Life and Paleoenvironment, Beijing 100044, China. Yuan-Qing Wang [wangyuanqing@ivpp.ac.cn 
], Key Laboratory of Vertebrate Evolution and Human Origins of Chinese Academy of Sciences, Institute of Vertebrate Paleontology and Paleoanthropology, Chinese Academy of Sciences, Beijing 100044, China; CAS Center for Excellence in Life and Paleoenvironment, Beijing 100044, China; College of Earth and Planetary Sciences, University of Chinese Academy of Sciences Beijing 100049, China. Xin-Yue Zhang [zhangxinyue@ivpp.ac.cn ], Key Laboratory of Vertebrate Evolution and Human Origins of Chinese Academy of Sciences, Institute of Vertebrate Paleontology and Paleoanthropology, Chinese Academy of Sciences, Beijing 100044, China; CAS Center for Excellence in Life and Paleoenvironment, Beijing 100044, China; University of Chinese Academy of Sciences, Beijing 100049, China. Jin Meng [jmeng@amnh.org], Division of Paleontology, American Museum of Natural History New York 10024, USA; Key Laboratory of Vertebrate Evolution and Human Origins of Chinese Academy of Sciences, Institute of Vertebrate Paleontology and Paleoanthropology, Chinese Academy of Sciences, Beijing 100044, China; Earth and Environmental Sciences, Graduate Center, City University of New York, New York, 10016, USA.

This is an open-access article distributed under the terms of the Creative Commons Attribution License (for details please see creativecommons.org), which permits unrestricted use, distribution, and reproduction in any medium, provided the original author and source are credited.

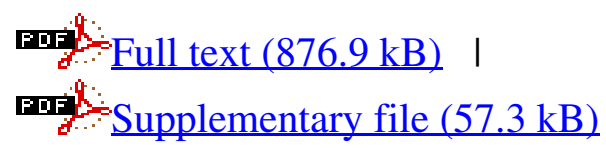

